\section{NICE}<smiles>C1CCC1</smiles>

guideline

\title{
Physical health of people in prison
}

NICE guideline

Published: 2 November 2016

nice.org.uk/guidance/ng57 


\section{Your responsibility}

The recommendations in this guideline represent the view of NICE, arrived at after careful consideration of the evidence available. When exercising their judgement, professionals are expected to take this guideline fully into account, alongside the individual needs, preferences and values of their patients or service users. The application of the recommendations in this guideline are not mandatory and the guideline does not override the responsibility of healthcare professionals to make decisions appropriate to the circumstances of the individual patient, in consultation with the patient and/or their carer or guardian.

Local commissioners and/or providers have a responsibility to enable the guideline to be applied when individual health professionals and their patients or service users wish to use it. They should do so in the context of local and national priorities for funding and developing services, and in light of their duties to have due regard to the need to eliminate unlawful discrimination, to advance equality of opportunity and to reduce health inequalities. Nothing in this guideline should be interpreted in a way that would be inconsistent with compliance with those duties. 


\section{Contents}

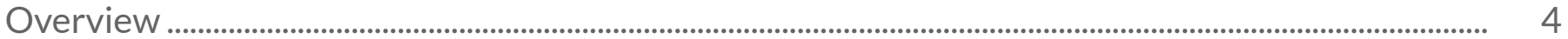

Who is it for?

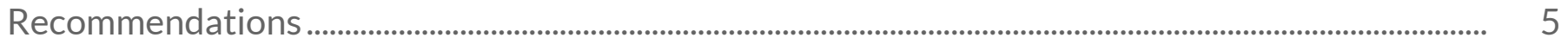

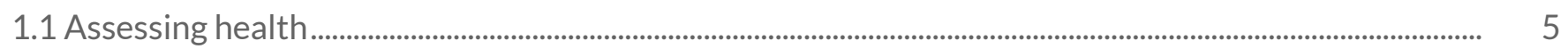

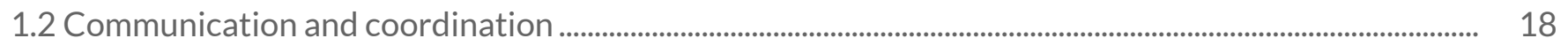

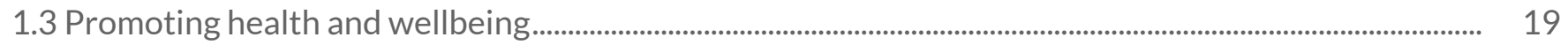

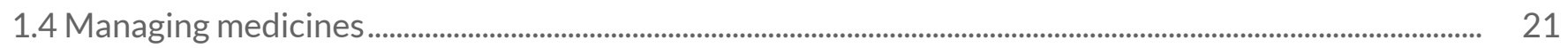

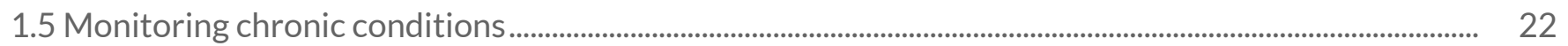

1.6 Managing deteriorating health and health emergencies........................................................................................ 23

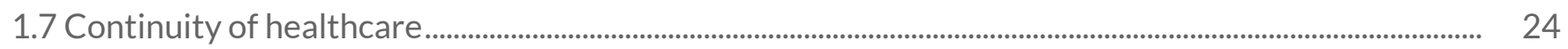

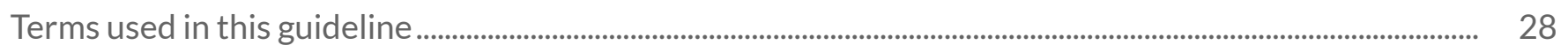

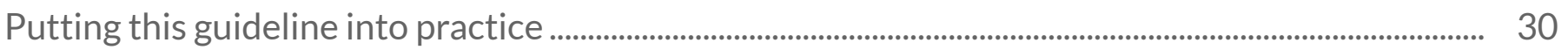

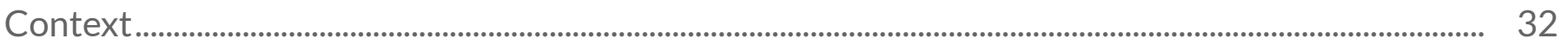

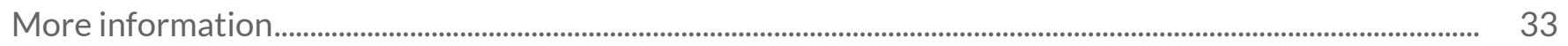

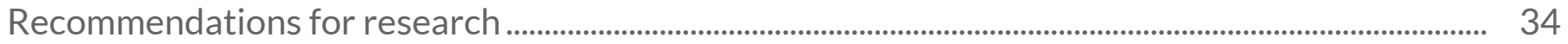

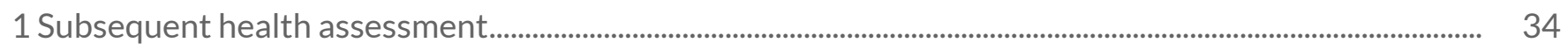

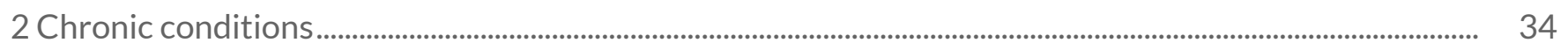

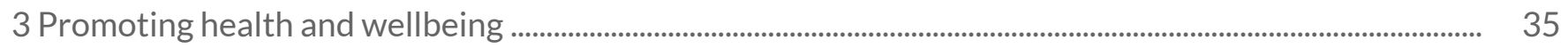

4 Assessment tools for health promotion ................................................................................................................

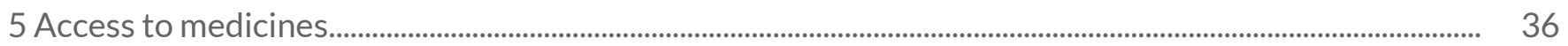




\section{Overview}

This guideline covers assessing, diagnosing and managing physical health problems of people in prison. It aims to improve health and wellbeing in the prison population by promoting more coordinated care and more effective approaches to prescribing, dispensing and supervising medicines.

Please note: Recommendations on ongoing mental health care will be included in NICE's guideline on mental health of adults in contact with the criminal justice system, due to publish in February 2017.

Who is it for?

- Practitioners and managers working in prisons or young offender institutions

- Providers of care and support to people in prisons or young offender institutions

- People in prisons or young offender institutions, and their families and carers. 


\section{Recommendations}

People have the right to be involved in discussions and make informed decisions about their care, as described in your care.

Making decisions using NICE guidelines explains how we use words to show the strength (or certainty) of our recommendations, and has information about prescribing medicines (including off-label use), professional guidelines, standards and laws (including on consent and mental capacity), and safeguarding.

\subsection{Assessing health}

\section{First-stage health assessment at reception into prison}

1.1.1 At first reception into prison, a healthcare professional (or trained healthcare assistant under the supervision of a registered nurse) should carry out a health assessment for every person. Do this before the person is allocated to their cell. As part of the assessment, identify:

- any issues that may affect the person's immediate health and safety before the secondstage health assessment

- priority health needs to be addressed at the next clinical opportunity.

1.1.2 Ensure continuity of care for people transferring from one custodial setting to another (including court, the receiving prison or during escort periods) by, for example:

- accessing relevant information from the patient clinical record, prisoner escort record and cell sharing risk assessment

- checking medicines and any outstanding medical appointments.

1.1.3 Take into account any communication needs or difficulties the person has (including reading and writing ability), and follow the principles in NICE's guideline on patient experience in adult NHS services.

1.1.4 The first-stage health assessment should include the questions and actions in table 1. It should cover: 
- physical health

- alcohol use

- substance misuse

- mental health

- self-harm and suicide risk.

Table 1 Questions for first-stage health assessment

\begin{tabular}{|c|c|}
\hline Topic questions & Actions \\
\hline \multicolumn{2}{|l|}{ Prison sentence } \\
\hline $\begin{array}{l}\text { 1. Has the person committed murder, } \\
\text { manslaughter or another offence with a } \\
\text { long sentence? }\end{array}$ & $\begin{array}{l}\text { Yes: refer the person for mental health } \\
\text { assessment by the prison mental health in-reach } \\
\text { team if necessary. } \\
\text { No: record no action needed. }\end{array}$ \\
\hline \multicolumn{2}{|l|}{ Prescribed medicines } \\
\hline $\begin{array}{l}\text { 2. Is the person taking any prescribed } \\
\text { medicines (for example, insulin) or over-the- } \\
\text { counter medicines (such as creams or } \\
\text { drops)? If so: } \\
\text { - what are they } \\
\text { - what are they for } \\
\text { - how do they take them? }\end{array}$ & $\begin{array}{l}\text { Yes: document any current medicines being } \\
\text { taken and generate a medicine chart. } \\
\text { Refer the person to the prescriber for } \\
\text { appropriate medicines to be prescribed, to } \\
\text { ensure continuity of medicines. } \\
\text { If medicines are being taken, ensure that the } \\
\text { next dose has been provided (see } \\
\text { recommendations } 1.7 .10 \text { and } 1.7 .11 \text { ). } \\
\text { Let the person know that medicines } \\
\text { reconciliation will take place before the second- } \\
\text { stage health assessment. } \\
\text { No: record no action needed. }\end{array}$ \\
\hline
\end{tabular}


3. Has the person received any physical injuries over the past few days, and if so:

- what were they

- how were they treated?
Yes: assess severity of injury, any treatment received and record any significant head, abdominal injuries or fractures.

Document any bruises or lacerations observed on a body map.

In very severe cases, or after GP assessment, the person may need to be transferred to an external hospital. Liaise with prison staff to transfer the person to the hospital emergency department by ambulance.

If the person has made any allegations of assault, record negative observations as well (for example, 'no physical evidence of injury').

No: record no action needed.

\section{Other health conditions}

4. Does the person have any of the following:

- allergies, asthma, diabetes, epilepsy or history of seizures

- chest pain, heart disease

- chronic obstructive pulmonary disease

- tuberculosis, sickle cell disease

- hepatitis B or C virus, HIV, other sexually transmitted infections

- learning disabilities

- neurodevelopmental disorders

- physical disabilities?
Ask about each condition listed.

Yes: make short notes on any details of the person's condition or management. For example, 'Asthma - on Ventolin 1 puff daily'.

Make appointments with relevant clinics or specialist nurses if specific needs have been identified.

No: record no action needed. 


\begin{tabular}{|c|c|}
\hline $\begin{array}{l}\text { 5. Are there any other health problems the } \\
\text { person is aware of that have not been } \\
\text { reported? }\end{array}$ & $\begin{array}{l}\text { Yes: record the details and check with the person } \\
\text { that no other physical health complaint has been } \\
\text { overlooked. } \\
\text { No: record no action needed. }\end{array}$ \\
\hline $\begin{array}{l}\text { 6. Are there any other concerns about the } \\
\text { person's health? }\end{array}$ & $\begin{array}{l}\text { Yes: make a note of any other concerns about } \\
\text { physical health. This should include any health- } \\
\text { related observations about the person's physical } \\
\text { appearance (for example, weight, pallor, } \\
\text { jaundice, gait or frailty). } \\
\text { Refer the person to the GP or relevant clinic. } \\
\text { No: note 'Nil'. }\end{array}$ \\
\hline \multicolumn{2}{|l|}{ Additional questions for women } \\
\hline $\begin{array}{l}\text { 7. Does the woman have reason to think she } \\
\text { is pregnant, or would she like a pregnancy } \\
\text { test? }\end{array}$ & $\begin{array}{l}\text { If the woman is pregnant, refer to the GP and } \\
\text { midwife. } \\
\text { If there is reason to think the woman is pregnant, } \\
\text { or would like a pregnancy test: provide a } \\
\text { pregnancy test. Record the outcome. If positive, } \\
\text { make an appointment for the woman to see the } \\
\text { GP and midwife. } \\
\text { No: record response. }\end{array}$ \\
\hline \multicolumn{2}{|l|}{ Living arrangements, mobility and diet } \\
\hline $\begin{array}{l}\text { 8. Does the person need help to live } \\
\text { independently? }\end{array}$ & $\begin{array}{l}\text { Yes: note any needs. Liaise with the prison } \\
\text { disability lead in reception about: } \\
\text { - the location of the person's cell } \\
\text { - further disability assessments the prison may } \\
\text { need to carry out. } \\
\text { No: record response. }\end{array}$ \\
\hline $\begin{array}{l}\text { 9. Do they use any equipment or aids (for } \\
\text { example, walking stick, hearing aid, glasses, } \\
\text { dentures, continence aids or stoma)? }\end{array}$ & $\begin{array}{l}\text { Yes: remind prison staff that all special } \\
\text { equipment and aids the person uses should } \\
\text { follow them from reception to their cell. } \\
\text { No: record response. }\end{array}$ \\
\hline
\end{tabular}


10. Do they need a special medical diet?

Yes: confirm the need for a special medical diet. Note the medical diet the person needs and send a request to catering. Refer to appropriate clinic for ongoing monitoring.

No: record response.

Past or future medical appointments

11. Has the person seen a doctor or other healthcare professional in the past few months? If so, what this was for?

Yes: note details of any recent medical contact. Arrange a contact letter to get further information from the person's doctor or specialist clinic. Note any ongoing treatment the person needs and make appointments with relevant clinics, specialist nurses, GP or other healthcare staff.

No: record no action needed.

12. Does the person have any outstanding Yes: note future appointment dates. Ask medical appointments? If so, who are they with, and when? healthcare administrative staff to manage these appointments or arrange for new dates and referral letters to be sent if the person's current hospital is out of the local area.

No: record no action needed.

Alcohol and substance misuse

13. Does the person drink alcohol, and if so:

- how much do they normally drink?

- how much did they drink in the week before coming into custody?

Urgently refer the person to the GP or an alternative suitable healthcare professional if:

- they drink more than 15 units of alcohol daily or

- they are showing signs of withdrawal or

- they have been given medication for withdrawal in police or court cells.

No: record response. 
14. Has the person used street drugs in the last month? If so, how frequently?

When did they last use:

- heroin

- methadone

- benzodiazepines

- amphetamine

- cocaine or crack

- novel psychoactive substances

- cannabis

- anabolic steroids

- performance and image enhancing drugs?
Yes: refer the person to substance misuse services if there are concerns about their immediate clinical management and they need immediate support. Take into account whether:

- they have taken drugs intravenously

- they have a positive urine test for drugs

- their answers suggest that they use drugs more than once a week

- they have been given medication for withdrawal in police or court cells.

If the person has used intravenous drugs, check them for injection sites. Refer them to substance misuse services if there are concerns about their immediate clinical management and they need immediate support.

No: record response.

Problematic use of prescription medicines

15. Has the person used prescription or over-the-counter medicines in the past month:

- that were not prescribed or recommended for them or

- for purposes or at doses that were not prescribed?

- If so, what was the medicine and how did they use it (frequency and dose)?

Yes: refer the person to substance misuse services if there are concerns about their immediate clinical management and they need immediate support.

No: record response. 


\begin{tabular}{|c|c|}
\hline $\begin{array}{l}\text { 16. Has the person ever seen a healthcare } \\
\text { professional or service about a mental } \\
\text { health problem (including a psychiatrist, GP, } \\
\text { psychologist, counsellor, community mental } \\
\text { health services, alcohol or substance misuse } \\
\text { services or learning disability services)? } \\
\text { If so, who did they see and what was the } \\
\text { nature of the problem? }\end{array}$ & $\begin{array}{l}\text { Yes: refer the person for a mental health } \\
\text { assessment if they have previously seen a mental } \\
\text { health professional in any service setting. } \\
\text { No: record response. }\end{array}$ \\
\hline $\begin{array}{l}\text { 17. Has the person ever been admitted to a } \\
\text { psychiatric hospital, and if so: } \\
\text { - when was their most recent discharge } \\
\text { - what is the name of the hospital } \\
\text { - what is the name of their consultant? }\end{array}$ & $\begin{array}{l}\text { Yes: refer the person for a mental health } \\
\text { assessment. } \\
\text { No: record response. }\end{array}$ \\
\hline $\begin{array}{l}\text { 18. Has the person ever been prescribed } \\
\text { medicine for any mental health problems? If } \\
\text { so: } \\
\text { - what was the medicine } \\
\text { - when did they receive it } \\
\text { - when did they take the last dose } \\
\text { - what is the current dose (if they are still } \\
\text { taking it) } \\
\text { - when did they stop taking it? }\end{array}$ & $\begin{array}{l}\text { Yes: refer the person for a mental health } \\
\text { assessment if they have taken medicine for } \\
\text { mental health problems. } \\
\text { No: record response }\end{array}$ \\
\hline
\end{tabular}


19. Is the person:

- feeling hopeless or

- currently thinking about or planning to harm themselves or attempt suicide?
Yes: refer the person for an urgent mental health assessment. Open an Assessment, Care in

Custody and Teamwork (ACCT) plan if:

- there are serious concerns raised in response to questions about self-harm, including thoughts, intentions or plans, or observations (for example, the patient is very withdrawn or agitated) or

- the person has a history of previous suicide attempts.

Be aware and record details of the impact of the sentence on the person, changes in legal status and first imprisonment, and the nature of the offence (for example, murder, manslaughter, offence against the person and sexual offences). No: record response.

Yes: refer the person for a mental health assessment if they have ever tried to harm themselves.

No: record response.

- was this inside or outside prison

- when was the most recent incident

- what was the most serious incident?

\section{Following the first-stage health assessment}

1.1.5 Give the person advice about how to contact prison health services and book GP appointments in the future.

1.1.6 Ask the person for consent to transfer their medical records from their GP to the prison healthcare service (see recommendations 1.7.1 and 1.7.2 for more information about transfer of medical records). 
1.1.7 Enter in the person's medical record:

- all answers to the reception health assessment questions

- health-related observations, including those about behaviour and mental state (including eye contact, body language, rapid, slow or strange speech, poor hygiene, strange thoughts)

- details of any action taken.

1.1.8 Carry out a medicines reconciliation (in line with NICE's guideline on medicines optimisation) before the second-stage health assessment. See also recommendations $\underline{1.4 .1}$ and $\underline{1.7 .10}$ for recommendations on risk assessments for in-possession medicines and ensuring continuity of medicine.

\section{Tuberculosis screening within 48 hours}

The recommendations in this section have been adapted from the NICE guideline on tuberculosis (TB).

1.1.9 Healthcare professionals in prisons should ensure people coming into prison are screened for TB within 48 hours of arrival.

1.1.10 Report all suspected and confirmed TB cases to the local multidisciplinary TB team within 1 working day.

1.1.11 If a case of TB is confirmed:

- Arrange for the local multidisciplinary TB team to visit within 5 working days.

- Contact the local Public Health England unit and multidisciplinary TB team to arrange a contact investigations exercise. They should also consider using mobile $\mathrm{X}$-ray to check for further cases.

1.1.12 Put contingency, liaison and handover plans in place to ensure continuity of care before a person being treated for TB is transferred between prisons or released. Any other agencies working with the person should also be involved in this planning. 


\section{Second-stage health assessment within 7 days}

1.1.13 A healthcare professional (for example, a registered general nurse) should carry out a second-stage health assessment for every person in prison. Do this within 7 days of the first-stage health assessment, and include as a minimum:

- reviewing the actions and outcomes from the first-stage health assessment

- asking the person about:

- any previous misuse of alcohol, use of drugs or improper use of prescription medicine

- if they have ever suffered a head injury or lost consciousness, and if so:

$\diamond$ how many times this has happened

$\diamond$ whether they have ever been unconscious for more than 20 minutes

$\diamond$ whether they have any problems with their memory or concentration

- smoking history

- the date of their last sexual health screen

- any history of serious illness in their family (for example, heart disease, diabetes, epilepsy, cancer or chronic conditions)

- their expected release date, and if less than 1 month plan a pre-release health assessment: see recommendation 1.7.5

- whether they have ever had a screening test (for example, a cervical screening test or mammogram)

- whether they have, or have had, any gynaecological problems

- measuring and recording the person's height, weight, pulse, blood pressure and temperature, and carrying out a urinalysis.

1.1.14 Review the person's first- and second-stage health assessment records, medical history, GP and vaccination records and: 
- Refer the person to the GP or a relevant clinic if further assessment is needed. See, for example, NICE's guidelines on cardiovascular disease (recommendations on identifying people for full formal risk assessment) or type 2 diabetes (the recommendation on risk assessment).

- Arrange a follow-up appointment if needed.

1.1.15 Consider using the Correctional Mental Health Screen for Men (CMHS-M) or Women (CMHS-W) to identify possible mental health problems if:

- the person's history, presentation or behaviour suggests they may have a mental health problem

- the person's responses to the first-stage health assessment suggest they may have a mental health problem

- the person has a chronic physical health problem with associated functional impairment

- concerns have been raised by other agencies about the person's abilities to participate in the criminal justice process.

1.1.16 When using the CMHS-M or CMHS-W with a transgender person, use the measure that is in line with their preferred gender identity.

1.1.17 If there is other evidence supporting the likelihood of mental health problems, or a man scores 6 or more on the CMHS-M, or a woman scores 4 or more on the CMHS-W:

- a practitioner who is trained to perform an assessment of mental health problems should conduct further assessment or

- a practitioner who is not trained to perform an assessment of mental health problems should refer the person to an appropriately trained professional for further assessment.

1.1.18 Offer people tailored health advice based on their responses to the assessment questions. This should be in a variety of formats (including face-to-face). It should include advice on:

- alcohol (see NICE's guideline on alcohol-use disorders) 
- substance misuse (see NICE's guideline on drug misuse in over 16s)

- exercise (see recommendations 1.3.3 and 1.3.4)

- $\operatorname{diet}$ (see recommendation 1.3.5)

- stopping smoking (see recommendation 1.3.6)

- sexual health (see recommendations 1.3.7 and 1.3.8).

1.1.19 Offer the person advice, with supporting literature if appropriate, on:

- how to contact prison health services and book GP appointments or other clinics, for example, dental, optician, chiropodist, substance misuse and recovery services

- where to find health information that is accessible and understandable

- how to attend or get a referral to attend any health-promoting activities in the future (see recommendations 1.3.1-1.3.8)

- medicines adherence (see recommendation 1.4.7).

1.1.20 Enter in the person's medical record:

- all answers to the second-stage health assessment questions

- health-related observations

- details of any action taken.

1.1.21 Plan a follow-up healthcare review at a suitable time based on clinical judgement, taking into account the age of the person and length of their sentence. For people who may be in prison for less than 1 month, see recommendation 1.7.5.

\section{Health checks and screening}

1.1.22 Ensure that there is a system and processes in place to carry out and refer to other assessments in line with recommendations in NICE guidelines. 


\section{Hepatitis B and C}

The recommendations in this section have been adapted from the NICE guideline on hepatitis B and $\mathrm{C}$ testing.

1.1.23 Prison healthcare services (working with the NHS lead for hepatitis) should ensure that:

- all people are offered a hepatitis B vaccination when entering prison (for the vaccination schedule, refer to the Green Book)

- all people are offered access to confidential testing for hepatitis B and C when entering prison and during their detention

- people who test for hepatitis B or C receive the results of the test, regardless of their location, when they become available

- results from hepatitis B and C testing are provided to the person's community-based $\mathrm{GP}$, if consent is given.

\section{HIV}

The recommendations in this section have been adapted from the NICE guideline on HIV testing.

1.1.24 Offer all people HIV testing when entering prison.

1.1.25 Primary care providers should ensure annual HIV testing is part of the integrated healthcare offered to men who are known to have sex with men.

1.1.26 Provide information on HIV testing and discuss why it is recommended (including to those who indicate that they may wish to decline the test).

1.1.27 Conduct post-test discussions, including giving positive test results and delivering post-test and general health promotion interventions.

1.1.28 Recognise illnesses that may signify primary HIV infection and clinical indicator diseases that often coexist with HIV. 


\section{Sexually transmitted infections (STIs)}

The recommendations in this section have been adapted from the NICE guideline on sexually transmitted infections.

1.1.29 Identify people at high risk of STIs using their sexual history. Opportunities for risk assessment may arise during consultations on contraception, pregnancy or abortion, and when carrying out a cervical smear test or offering an STI test. Risk assessment could also be carried out during routine care or when a new patient registers.

1.1.30 Have structured, one-to-one discussions with people at high risk of STIs (if trained in sexual health), or arrange for these discussions to take place with a trained practitioner.

\section{Other health checks and screening}

1.1.31 Offer people equivalent health checks to those offered in the community, for example:

- the NHS health check programme

- learning disabilities annual health check

- relevant NHS screening programmes, such as those for abdominal aortic aneurysm and bowel, breast and cervical cancer.

\subsection{Communication and coordination}

1.2.1 Ensure that the different teams (including prison staff) that manage a person's care in prison communicate with one another to coordinate care.

1.2.2 Share information with other health and social care staff, offender supervisors and probation providers who are involved in the person's care in prison if necessary for the person's care.

1.2.3 Ensure that people with complex health and social care needs have a lead care coordinator responsible for managing their care. Ensure that the person and all healthcare and prison staff know who this is. 
1.2.4 Share relevant information about people with complex needs with prison staff using prison record systems in line with legislation and national guidance. This should include information about any high-level risks, such as:

- risk of self-harm

- risk to others

- communicable diseases

- epilepsy

- diabetes

- allergies

- deteriorating health conditions

- learning disabilities.

1.2.5 Review people in prison with complex health and social care needs. Ensure that if a person is supported by a multidisciplinary team, the teams meet regularly to plan and coordinate ongoing management. These should be facilitated by primary care.

1.2.6 Document all health and social care patient interactions and any information related to health and social care in the person's primary care patient record.

\subsection{Promoting health and wellbeing}

\section{General health advice}

1.3.1 Consider using peer support and mentoring to help promote a healthy lifestyle while in prison.

1.3.2 Offer people in prison tailored health information in a variety of formats, including face-to-face. Include advice about:

- exercise

- diet 
- stopping smoking

- sexual health

- personal hygiene, including oral hygiene.

\section{Exercise}

1.3.3 Encourage people to be physically active. Offer them information about:

- the benefits of exercise

- what exercise facilities are provided, where they are and how they can use them, for example:

- going to the gym

- using the exercise yard

- exercises that can be done in the cell.

1.3.4 Offer people information and advice in line with recommendations in the NICE guidelines on:

- physical activity: brief advice for adults in primary care

- physical activity: exercise referral schemes

- preventing excess weight gain

- obesity: identification, assessment and management (section 1.6 on physical activity).

\section{Diet}

1.3.5 Offer people information about:

- the benefits of a healthy diet

- healthier food options available in the prison.

See section 1.7 on dietary advice in NICE's guideline on obesity: identification, assessment and management. 


\section{Stopping smoking}

1.3.6 Offer people in prison information about:

- the risks of smoking

- support available to stop as part of smoking cessation services (for example, nicotine patches and motivational support).

See the NICE pathway on smoking.

\section{Sexual health}

1.3.7 Offer people in prison information about sexually transmitted infections and available sexual health services.

1.3.8 Ensure that people in prison have discreet access to condoms, dental dams and water-based lubricants without the need to ask for them.

\subsection{Managing medicines}

\section{Access to medicines}

1.4.1 Carry out an individual risk assessment to determine if the person can hold their medicines in-possession. Allow people in prison to hold all medicine inpossession unless the person does not pass the risk assessment.

1.4.2 Directly observe the administration of all schedule 2 and 3 medicines (also see NICE's guideline on controlled drugs) and medicines for tuberculosis (see NICE's guideline on tuberculosis).

1.4.3 Directly observe the administration of any medicine that is not in-possession.

1.4.4 Work with prison staff to ensure a system is in place to:

- supervise the administering of medicines not held in-possession to maximise adherence

- allow timings of medicines doses to align with the prescribed dose regime 
- reduce diversion (passing medicines on to other people)

- protect confidentiality.

See the section on supporting adherence in NICE's guideline on medicines adherence.

1.4.5 Review and (if necessary) repeat a person's risk assessment for in-possession medicine if the person's circumstances change. Involve a multidisciplinary team if needed, including prison staff and the person. Examples of when the risk assessment should be repeated include:

- if carrying out a medicines review

- if a person is considered able to manage their own medicines after a period of having medicines not in-possession

- if there is a medicine safety incident, including evidence of self-harm

- if someone has raised security concerns (for example, about bullying, diversion or hoarding)

- if the person has not been taking their prescribed medicines

- if there is concern about the person's ability to self-medicate

- when following the Assessment Care in Custody and Teamwork care planning approach

- if the person is transferred to or from a segregation unit.

1.4.6 Consider providing storage for in-possession medicine in prison cells, for example, a lockable cupboard.

1.4.7 Give people in prison information and education about medicines adherence (see the section on patient involvement in decisions about medicines in NICE's guideline on medicines adherence).

\subsection{Monitoring chronic conditions}

1.5.1 Monitor people with chronic conditions in accordance with the following NICE guidelines: 
- chronic heart failure

- chronic kidney disease

- chronic obstructive pulmonary disease

- epilepsies

- hypertension

- secondary prevention of myocardial infarction

- type 1 diabetes and type 2 diabetes.

See also the NICE quality standard on asthma.

1.5.2 Monitor people with chronic conditions that need specialist management in line with relevant NICE guidelines (for example, hepatitis B [chronic] and colorectal cancer).

1.5.3 Consider more frequent monitoring for older people and people with chronic conditions (such as diabetes) who are serving longer prison sentences.

\subsection{Managing deteriorating health and health emergencies}

1.6.1 Ensure a local protocol is available for responding to and managing situations in which a person's health quickly deteriorates, or in a health emergency. This could include, for example:

- essential training for front-line prison staff, including the first person likely to be on the scene in an emergency

- processes to enable healthcare staff to reach a person in prison quickly, such as how to gain access to their cell

- processes to ensure a person can be quickly seen by a healthcare professional if their health deteriorates quickly

- availability of emergency equipment, such as emergency grab bags 
- recording the actions and observations taken by prison and healthcare staff when assessing people with rapidly deteriorating health or in an emergency situation, such as:

- updating a person's care plan or

- recommendations for immediate follow-up

- a clear care plan for supporting people with rapidly deteriorating health

- guidance on sharing information between prison staff and healthcare staff, such as details on standardised clinical handovers and follow-up.

1.6.2 Ensure prison and healthcare staff are made aware of people who have underlying chronic conditions and allergies:

- if the person agrees (in line with the local information-sharing policies)

- in emergencies, in line with the duty of healthcare staff to share relevant confidential patient data.

\subsection{Continuity of healthcare}

\section{On entry into prison}

1.7.1 Arrange for the person's medical records to be transferred from primary and secondary care to the prison healthcare team on the person's entry to prison (see recommendation 1.1.6).

1.7.2 Primary and secondary care services should provide information from the person's medical records to the prison healthcare team that is:

- relevant

- in the person's best interests.

\section{Transit between custodial settings}

1.7.3 Ensure continuity of care between custodial settings, including court, the receiving prison or during escort periods by, for example:

- providing access to relevant information from the patient record 
- providing any medicines (including controlled drugs) - see also recommendations 1.7.10-1.7.16 on continuity of medicines

- issuing an FP10 prescription.

\section{Before release from prison}

1.7.4 Carry out a pre-release health assessment for people with complex needs. This should be led by primary healthcare and involve multidisciplinary team members and the person. It should take place at least 1 month before the date the person is expected to be released.

1.7.5 For people who may be in prison for less than 1 month, plan pre-release health assessments during the second-stage health assessment (see recommendation 1.1.13 for details of this assessment).

1.7.6 Include the following in the care summary and post-release action plan for all people:

- any significant health events that affected the person while they were in prison, for example:

- new diagnoses

- hospital admissions

- instances of self-harm

- any health or social care provided in prison

- details of any ongoing health and social care needs, including:

- medicines they are taking (see also recommendations 1.7.12-1.7.14)

- mental health or substance misuse

- future health and social care appointments, including appointments with:

- secondary and tertiary care

- mental health services

- substance misuse and recovery services 
- social services.

1.7.7 Give the person a copy of the care summary and post-release plan.

1.7.8 Help people who are being released from prison to find and register with a community GP if they were not previously registered with one.

1.7.9 Before the person is released, liaise with services that will be providing care and support to them after they leave prison. This should include (as needed):

- primary care

- secondary and tertiary specialist services (for example, HIV, TB, oncology)

- mental health or learning disability services

- substance misuse services

- National Probation Service

- community rehabilitation company (CRC)

- social services

- family or carers

- external agencies such as home care.

\section{Continuity of medicines}

1.7.10 Ensure the person can keep taking their medicines after coming into prison.

1.7.11 Give critical medicines in a timely way to prevent harm from missed or delayed doses. Use the examples of critical medicines in table 2 in conjunction with clinical judgement and any safety alerts.

Table 2 Examples of critical medicines where timeliness of administration is crucial to prevent harm from missed and delayed doses

This table contains examples only and should be used in conjunction with clinical judgement. It is important to assess each person on an individual basis. 


\begin{tabular}{|c|c|}
\hline Area & Medicines \\
\hline Cardiovascular system & $\begin{array}{l}\text { Anticoagulants } \\
\text { Nitrates }\end{array}$ \\
\hline Respiratory system & $\begin{array}{l}\text { Adrenoceptor agonists } \\
\text { Antimuscarinic bronchodilators } \\
\text { Adrenaline for allergic emergencies }\end{array}$ \\
\hline Central nervous system & $\begin{array}{l}\text { Anti-epileptic drugs } \\
\text { Drugs used in psychoses and related disorders } \\
\text { Drugs used in parkinsonism and related disorders } \\
\text { Drugs used to treat substance misuse }\end{array}$ \\
\hline Infections & $\begin{array}{l}\text { As clinically indicated, such as anti-infectives or anti- } \\
\text { retrovirals }\end{array}$ \\
\hline Endocrine system & $\begin{array}{l}\text { Corticosteroids } \\
\text { Drugs used in diabetes }\end{array}$ \\
\hline $\begin{array}{l}\text { Obstetrics, gynaecology and } \\
\text { urinary tract disorders }\end{array}$ & Emergency contraceptives \\
\hline $\begin{array}{l}\text { Malignant disease and } \\
\text { immunosuppression }\end{array}$ & $\begin{array}{l}\text { Drugs affecting the immune response } \\
\text { Sex hormones and hormone antagonists in malignant } \\
\text { disease - depot preparations }\end{array}$ \\
\hline Nutrition and blood & Parenteral vitamins $B$ and $C$ \\
\hline Eye & $\begin{array}{l}\text { Corticosteroids and other anti-inflammatory } \\
\text { preparations } \\
\text { Local anaesthetics } \\
\text { Mydriatics and cycloplegics } \\
\text { Glaucoma treatment }\end{array}$ \\
\hline \multicolumn{2}{|c|}{$\begin{array}{l}\text { Based on UKMi NPSA Rapid Response Report: Reducing harm from omitted and delayed } \\
\text { medicines in hospital. Revised January } 2016 .\end{array}$} \\
\hline
\end{tabular}

1.7.12 Hold a one-to-one discussion with the person to agree a plan for how they will take their medicine after their release from prison. This should include education about taking prescribed medicines. 
1.7.13 Consider carrying out a medicines review for people who are assessed as needing extra support to manage their medicines on release or transfer from prison. For example:

- people with TB, HIV, diabetes, substance misuse or mental health problems

- people with neurodevelopmental disorders or learning disabilities

- people receiving end of life care

- older people

- people serving long-term sentences.

1.7.14 When a person is discharged or transferred from prison, give them a minimum of 7 days' prescribed medicines or an FP10 prescription, based on a risk assessment.

1.7.15 Set up a process to ensure that people being discharged or transferred at short notice from prison are given a supply of their medicines or an FP10 prescription.

1.7.16 For recommendations on care for people moving from prison to another care setting, see the section on medicines-related communication systems in NICE's guideline on medicines optimisation.

\section{Terms used in this guideline}

\section{Body map}

A diagram of the body on which physical injuries can be recorded.

\section{Diversion}

The transfer of any prescription medicines from the person for whom they were prescribed to another person for misuse.

\section{FP10}

A prescription form. People who are released from prison unexpectedly can take an FP10 to a community pharmacy to receive their medicines free of charge until they can arrange to see their GP or register with a new GP. 


\section{Grab bags}

Medical emergency bags containing equipment and medication for dealing with common medical emergencies. The equipment may include dressings, automated external defibrillator and oxygen. It may also include medicine, for example, for treating allergic reactions (anaphylaxis).

\section{In-possession}

Medicine is said to be held in-possession if a person (usually in a prison or other secure setting) is responsible for holding and taking it themselves.

\section{Medicines reconciliation}

The process of identifying an accurate list of a person's current medicines and comparing them with the current list in use, recognising any discrepancies, and documenting any changes, thereby resulting in a complete list of medicines, accurately communicated. Adapted from definition by the Institute for Healthcare Improvement.

\section{Multidisciplinary team}

A group of professionals from different disciplines who each provide specific support to a person, working as a team. In prison settings, a multidisciplinary team may include physical and mental health professionals, prison staff, National Probation Service and/or community rehabilitation company (CRC) representatives, chaplains and staff from other agencies, such as immigration services and social care staff.

\section{Street drugs}

Substances taken for a non-medical purpose (for example, mood-altering, stimulant or sedative effects). 


\section{Putting this guideline into practice}

NICE has produced tools and resources to help you put this guideline into practice.

Putting recommendations into practice can take time. How long may vary from guideline to guideline, and depends on how much change in practice or services is needed. Implementing change is most effective when aligned with local priorities.

Changes recommended for clinical practice that can be done quickly - like changes in prescribing practice - should be shared quickly. This is because healthcare professionals should use guidelines to guide their work - as is required by professional regulating bodies such as the General Medical and Nursing and Midwifery Councils.

Changes should be implemented as soon as possible, unless there is a good reason for not doing so (for example, if it would be better value for money if a package of recommendations were all implemented at once).

Different organisations may need different approaches to implementation, depending on their size and function. Sometimes individual practitioners may be able to respond to recommendations to improve their practice more quickly than large organisations.

Here are some pointers to help organisations put NICE guidelines into practice:

1. Raise awareness through routine communication channels, such as email or newsletters, regular meetings, internal staff briefings and other communications with all relevant partner organisations. Identify things staff can include in their own practice straight away.

2. Identify a lead with an interest in the topic to champion the guideline and motivate others to support its use and make service changes, and to find out any significant issues locally.

3. Carry out a baseline assessment against the recommendations to find out whether there are gaps in current service provision.

4. Think about what data you need to measure improvement and plan how you will collect it. You may want to work with other health and social care organisations and specialist groups to compare current practice with the recommendations. This may also help identify local issues that will slow or prevent implementation. 
5. Develop an action plan, with the steps needed to put the guideline into practice, and make sure it is ready as soon as possible. Big, complex changes may take longer to implement, but some may be quick and easy to do. An action plan will help in both cases.

6. For very big changes include milestones and a business case, which will set out additional costs, savings and possible areas for disinvestment. A small project group could develop the action plan. The group might include the guideline champion, a senior organisational sponsor, staff involved in the associated services, finance and information professionals.

7. Implement the action plan with oversight from the lead and the project group. Big projects may also need project management support.

8. Review and monitor how well the guideline is being implemented through the project group. Share progress with those involved in making improvements, as well as relevant boards and local partners.

NICE provides a comprehensive programme of support and resources to maximise uptake and use of evidence and guidance. See our into practice pages for more information.

Also see Leng G, Moore V, Abraham S, editors (2014) Achieving high quality care - practical experience from NICE. Chichester: Wiley. 


\section{Context}

In April 2013 NHS England became responsible for commissioning all health services for people in prison in England. Healthcare in prison has a very important role in identifying significant health needs, maintaining health and detecting chronic conditions. This guideline supports equivalence of healthcare in prisons, a principle whereby health services for people in prisons are provided to the same standard, quality and specification as for patients in the wider NHS. Providing equivalence of care aims to address health needs, reduce health inequalities, prevent deterioration, reduce deaths from natural causes and ultimately assist rehabilitation and reduce reoffending.

The guideline population includes adults over 18 in prisons or young offender institutions. The prison population includes highly vulnerable groups such as:

- people with learning disabilities who find it difficult to understand the prison regime and what is happening to them

- older people and those serving longer sentences whose physical health often deteriorates or is exacerbated by previous lifestyle choices during imprisonment

- people serving short sentences, making it difficult for prison healthcare staff to achieve any sustainable change in their health

- people who have particular healthcare needs, such as:

- people with physical disabilities

- people with a history of substance misuse

- pregnant women.

Since 2006 there have been considerable changes in prison health services. But barriers to delivering health services in custodial settings still exist. These barriers make providing healthcare equivalent to what is available in the community a significant challenge. There are many recognised areas that the prison and healthcare systems need to address to manage the overall safety of people in prison. Key areas of focus for this guideline include:

- The initial reception assessment and subsequent general health assessments. This includes liaison and communication with external health organisations for the benefit of people's care while in prison or hospital, between establishments and on release. 
- Continuity of healthcare for those moving around the prison estate, including continuity of medicine, a coordinated approach between prison health services, and visiting health services and prison staff.

- Effective communication between teams, in particular when dealing with complex needs and sharing information to support people's care in the wider prison.

- Managing emergency situations, which can include high levels of complex needs within the prison population, the staff skills needed to work with this client group and the large numbers of people in prison moving across the prison estate.

- Procedures and methods to support people in transit between custodial settings or on release to the community.

This guidance should be read together with NICE's guideline on the mental health of adults in contact with the criminal justice system. People in prison often have a mix of physical and mental health issues during their sentence. Healthcare professionals working in prisons need a range of skills to assess, diagnose and manage physical health, mental health and addiction problems, as well as underlying complex social and behavioural issues.

\section{More information}

To find out what NICE has said on topics related to this guideline, see our web page on prisons and other secure settings. 


\section{Recommendations for research}

The guideline committee has made the following recommendations for research.

\section{Subsequent health assessment}

When should subsequent health assessments be carried out in prison for people serving long-term sentences?

\section{Why this is important}

Case management of chronic conditions in prison is difficult, and opportunities for self-care may be limited. The number of older people and people serving long sentences in prison is increasing. There is emerging anecdotal evidence that long-term incarceration exacerbates chronic ill health and causes early onset of conditions associated with old age. Research on this topic would help inform whether additional health checks may be needed to prevent potential health deterioration and quickly identify any new health-related conditions.

\section{Chronic conditions}

What is the prevalence of disease in the UK prison population?

\section{Why this is important}

At the time this guideline was published (November 2016), it was estimated that there were around 90,000 people in prison in the UK with an annual throughput of around 180,000 . To date, there is little clear evidence of the prevalence of disease among people in prison. This was highlighted by our reviews of chronic conditions (for which there was no disease prevalence data) and when searching for prevalence data for the health economic model.

Systems are now in place that will allow the relevant data to be gathered to inform a longitudinal study. Such a study would provide a useful starting point for a better understanding of how to shape healthcare provided to people in prison, both in terms of:

- meeting the needs of the prison population and

- providing commissioners with priority areas for developing and delivering health services. 


\section{Promoting health and wellbeing}

What is the most effective method for delivering health promotion activities and who should lead them (peers or professionals)?

\section{Why this is important}

There are few data on how health promotion interventions should be delivered and who is best to deliver them. People in prison sometimes find it challenging to use services provided by people they think are in positions of authority, such as prison officers and healthcare professionals. This is acknowledged in the qualitative review in this area.

There are many examples of health promotion activities, ranging from information leaflets to oneto-one sessions and group-based learning. If it can be shown which methods of health promotion are more effective, then both the NHS and prisons could better target their resources to inform, educate and support people to take a more active role in looking after themselves. This would lead to greater equivalence of service, a better experience of health promotion activities and more confidence in overall health provision.

\section{Assessment tools for health promotion}

What are the most effective tools to determine the health promotion needs of people in prison?

\section{Why this is important}

Health promotion in prison can vary and may not be seen as a priority by healthcare staff. But people in prison are entitled to an equivalent standard of healthcare to that which they would receive in the community. Prison offers an ideal opportunity to help people who perhaps have not previously attended health services. The prison population is known to have a high prevalence of smoking, often a poor diet and difficulties in accessing exercise programmes or information on sexual health. All of these may exacerbate existing health conditions or lead to poor health or infection.

No evidence was identified for health promotion needs assessment and a study would inform future recommendations in this area. An effective, valid assessment tool for identifying health promotion needs would ensure that people received care that met their needs. It may also identify specific healthcare needs more quickly so people can be given information and advice about selfcare, both in prison and after release. 


\section{Access to medicines}

Does the use of directly observed supply of named high-risk medicines (that is, not supplying the medicines to people to hold in-possession), reduce diversion, abuse and non-adherence?

\section{Why this is important}

Since 2003 self-administration of medicines by people in prison (known as holding medicines 'inpossession') has been encouraged. Directly observed administration is reserved for high-risk medicines and vulnerable patients. But different medicines are categorised as high risk by different prisons so the approach has been inconsistent. This is influenced by local factors including capacity. Delivering directly observed medicines is labour-intensive and difficult to include in the daily schedules of people in prison.

There is no evidence base underpinning which medicines should be administered under observation. This research would provide evidence to inform the development of a more consistent list of high-risk medicines that need direct observation to improve safety. The research would also inform commissioners of health and offender management services about the need to provide the workforce and operational capacity to administer high-risk medicines safely.

ISBN: 978-1-4731-2150-8

\section{Accreditation}

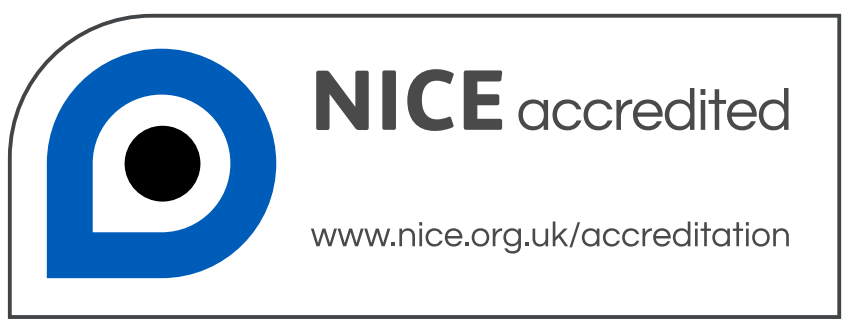

